\title{
Integrative Digital Transformation and Organizational Competitiveness(OC) : Proposal for a Transition Strategy to the Aeronautics Industry 4.0 (TSAI) based on a Knowledge Management(KM) approach in a Moroccan ecosystem environment.
}

\author{
Mohamed ETTAIBI ${ }^{(1, *)}$, MOKHTARI Bouchaib ${ }^{(1)}$ \\ ${ }^{(I, *)}$ Hassan First University of Settat, National School of Business and Management,, Research laboratory in Strategy \\ and Management of organizations. MOROCCO. m.ettaibi@uhp.ac.ma
}

\begin{abstract}
The objective of our paper is to transpose the Industrial Acceleration Plan 2.0 on the aeronautical industry in Morocco (IAM) by proposing a transition strategy to the aeronautical industry 4.0 (STIA 4.0). The latter will be based on the establishment of a transverse ecosystem (TSE) of knowledge management (KM) that will feed the innovation by strategic knowledge. The objective is to innovate through the exploitation of Big Data to implement the transverse ecosystem digital and renewable energy. This is justified by the fact that the digitization and decarbonization of industries have become the main vectors of competitiveness of companies in the aerospace industry 4.0. The choice of the latter, to conduct our study, is justified by the fact that it is a sector that requires digital resources to cope with its sophistication. Despite its complexity, it can be developed by own resources in the Moroccan context. That is why we have proposed this integrative strategy that integrates, in addition to digitalization, other resources (Barney, 1991) based on dynamic capabilities (Teece and all, 1997) and that takes into account the context and contextualization (Doha S. and Louitri A., 2020).
\end{abstract}

Key words : Integrative digital transformation, Innovation, Knowledge management, Organizational competitiveness, Transition to Aerospace Industry 4.0

\section{INTRODUCTION :}

Industry 4.0 offers real opportunities for the development of emerging countries. Moreover, His Majesty King Mohammed VI stressed in his speech of July 29, 2019, that "the renovation of the national development model is the prerequisite for the emergence of a new stage."[1]This Industry 4.0 represents a real opportunity for the takeoff of the Moroccan industrial sector. The establishment of smart factories and the integration of new information and communication technologies are more than ever the new determinants of performance and organizational competitiveness.

Thus, after having succeeded in the establishment of efficient ecosystems, the Industrial Acceleration Plan (IAP) should apprehend the new trends at the international level, including industry 4.0 , which is a great opportunity, not to be missed, to access a new stage of development.

In this context and to safeguard and improve the competitiveness and organizational performance of Moroccan companies, the government is preparing a second generation of the national plan for industrial

\footnotetext{
${ }^{1}$ Écosystèmes performants transverses

${ }^{2}$ This transverse digital ecosystem will be like the Digital Ecosystem Management (DEM)
}

acceleration called the PAI 2.0 to give it a digital dimension. This is a new industrial strategy that is an extension of the emergence plan and particularly its latest version, the National Industrial Acceleration Plan (PNAI) (2014-2020). Based on theshortcomings of the latter, this new plan will be a complement to the first 1.0 by the establishment of cross-cutting efficient ecosystems (ESPT) ${ }^{1}$.

The objective of our paper is to transpose this IAP (20212025) on the aerospace industry in Morocco (IAM) by proposing a strategy of digital transformation integrating (STDI) or strategy of transition to the aerospace industry 4.0 (STIA). The latter will be based on the establishment of a transverse ecosystem of knowledge management (KM) that will feed the innovation by strategic knowledge of digital type. The objective is to innovate more by exploiting Big Data to implement two other transverse ecosystems. These are the digital ${ }^{2}$ and renewable energy ecosystems. This is justified by the fact that digitization and decarbonization of industries have become the main vectors of competitiveness of companies especially in high-tech sectors such as the aerospace industry. The choice of the latter to conduct our study, which is proactive, is justified

The backbone and dynamo of the proposed STDI, which we will refer to in the following as EST(D) or (ECODIG) 
by the fact that it is a sector of the knowledge economy that requires specific digital resources to cope with its complexity and its sophistication. Despite the complexity of this sovereignty industry, we are convinced that it can be developed for its simplexity by own and endogenous resources in the Moroccan context. That is why we have proposed this integrative strategy that integrates, in addition to digitalization, other resources based on dynamic and organizational capabilities (Teece et all, 1997) [2] and that takes into account the context and contextualization (DOHA .S.and Louitri .A. 2020). [3]. It will be designed and modeled based on a transposition of the functioning of ecosystems in an ecological environment. This analog study between natural and business ecosystems will be carried out with completeness in a future article [4-5]

With this in mind, our research problem will be formulated as the following general question :

- How can the strategy of transition to the aeronautics industry 4.0 (STAI) be a new vector of organizational competitiveness within the companies of the aeronautics industry in Morocco (CAIM) ?

From this problem, two other sub-questions follow :

- What are the characteristics and specificities of STAI compared to conventional digitalization and digital transformation?

- How to design and implement a STAI within CAIM for their organizational competitiveness through innovation?

To answer these questions we propose to adopt the following plan :

The first part will be devoted to the theoretical and methodological framework of the study : It will seek to define first the main concepts of our wording in the framework of strategic management. It will then present the methodological approach and the theories to be mobilized to address our problem.

The second part will deal with a proposal for an interconceptual connection in the context of the aeronautical industry in Morocco (AIM).

The last part will attempt to design a conceptual model of the relations likely to exist between the concepts in the perspective of implementing the proposed STAI project within the companies of the aeronautical industry in Morocco $(C A I M)$ for their organizational competitiveness.

\section{Definition of a theoretical and methodological framework :}

This first part will be devoted to a review of the multidisciplinary literature that will focus on the definition and operationalization of the concepts of our theme. After having defined the meaning of each of them

\footnotetext{
${ }^{3}$ An analogous study between business and natural ecosystems will be conducted by us in the near future.
}

in its context, we will specify the criteria for the choice of the selected definitions in the perspective of exploring the relationship between STAI and Competitiveness via Knowledge management.

\subsection{Definition of concepts :}

We will successively define the following concepts: Knowledge management (KM), Digital transformation (DT), National industrial acceleration plan 2.0 (NIAP 2.0), Transverse ecosystem (TES), Transverse digital ecosystem (EST(D) or( ECODIG ),Transverse knowledge management ecosystem (ESPT(KM), Transverse innovation ecosystem (ECONOV), Transverse renewable energies ecosystem (ECOSER), Organizational competitiveness (OC), Aeronautical industry (AI).

This definitional work will be concluded by defining the concepts of ecological ecosystem and natural environment in order to identify the interactions between them. These interactions will be transposed to the design and configuration of the ecosystemic device that we propose in the field of $\mathrm{Al}^{3}$. This is a preparatory work for a future study on the transposition of the natural ecosystem on the business ecosystem (Hess, G. (2009) [6-7].

\subsubsection{Knowledge management (KM)}

Knowledge management is commonly called knowledge management (KM). The literature review shows that there are several definitions of this concept. We retain the one given by (Jean Louis Ermine, 2018)[8] because we consider it more complete and more adapted to our problem: "Knowledge Management in an organization is presented as "the management of activities and processes intended to amplify the use and creation of knowledge within an organization according to two complementary and strongly intertwined purposes: a patrimonial purpose (preservation, reuse and updating of knowledge) and a sustainable innovation purpose (active creation of individual knowledge and its integration at the collective level in an organization).

\subsubsection{The Digital Integration Transformation (DIT) :}

TDI is a concept that we designed to make a break with conventional digitalization and digital transformation. We conceived it because we believe that the latter is over, as Aurélie Jean [9] states: "I like to say that the digital transformation is over. "From there, we can define the DIT, which we propose as a strategy in this paper, as follows: "The digital-integrated transformation combines the use of digital tools (Twitter, Google, Facebook...), and the collection and analysis of data by an adapted knowledge management system. It integrates several material and immaterial resources such as Industry 4.0 technologies and dedicated digital skills. The latter are developed from the dynamic 
capabilities of organizations and human capital. It is designed and implemented respecting the specificities of its context investigation of competitiveness and organizational performance "4

\subsubsection{Industry Acceleration Plan 2.0 (IAP.2.0)}

It is a plan that is being prepared by the government as confirmed by the Minister of Trade and Industry Elalamy.M.H (2021) [10] "We are already preparing a plan for industrial acceleration 2.0 that will take over after 2020.this plan will give a very important part to innovation, R\&D, connected objects ... and will further promote the integration into the industrial economic fabric more Moroccan capital. "This new plan, which will have a digital dimension, will cover the period (20212025) and will give rise to cross-cutting ecosystems (EST) Seddiki. A. (2021) [11], namely the cross-cutting digital ecosystem (EST (D) or (ECODIG) and the cross-cutting innovation ecosystem (ECONOV).

In our paper, we propose to add two other ecosystems which are those of Knowledge management and renewable energies to take into account the post-Covid context which will be characterized by the knowledge economy and the new factors of competitiveness and organizational performance.

\subsubsection{EcosystemTransverse Digital (ESTD)}

According to the first statements in the specialized press, this ECODIG will be the main pillar of the new industrial strategy of Morocco which will be the subject of the PAI 2.0 in the field of Al. This ecosystem will be in charge of the piloting of the digital transformation within the EIAMs for their upgrading in terms of software and hardware and everything that concerns the infrastructure of the information systems of companies. He will be in charge of the digital veuille by making available to the aeronautical operators all the new technologies specific to the production process of aeronautical parts. It will accelerate the transition already initiated in the production of aircraft engine parts and composite material by facilitating the implementation of the technology of the aeronautical industry 4.0 in accordance with the STIA that we propose.

\subsubsection{Transverse Innovation Ecosystem (ECONOV)}

The establishment of this ECONOV must be provided by the PAI 2.0. From the research and development (R\&D) of universities working on Al and dedicated specialized institutes; this ecosystem will develop transverse innovations for the benefit of all aeronautical and related actors regardless of their specialization. These innovations will not only be technological and incremental but also organizational and managerial. We will give as an example of innovations, which are now urgent, those related to the procedures of decarbonization of aeronautical industries from renewable energies. This ecosystem will work in close collaboration with ECODIG especially in the development of Moroccan SMEs and SMIs in the aerospace sector.

\subsubsection{Transverse Ecosystem of Knowledge Management (TSE (KM)}

This ecosystemic configuration is not foreseen by the new version of the IPA and is a personal contribution to this paper. Based on our deep conviction that any digital transformation cannot be successful outside the context of the knowledge economy and based on our belief that this transformation will fail without the support of a dedicated, competent and qualified human capital. From all these convictions we believe that the projected PAI 2.0 must provide for the establishment of this ecosystem in its lover. This last one must be the support of all the others by endowing them with qualified human resources armed with digital knowledge. All this within the framework of a new digital approach which is the digitalo - integrating transformation. The transfer of Data from (EST(KM) to others will be done through a knowledge broker who will play the role of intermediation Munerol, L et Al (2013) [12]

\subsubsection{Transverse Ecosystem of Renewable Energies (ECOSER) :}

Starting from the new requirements of competitiveness and organizational performance in the industrial field, we propose in this article to set up in the ecosystemic device of the PAI 2.0 an ecosystem dedicated to renewable energy. It must take charge of the implementation of a strategy of decarbonization of Al from these energies especially as it has become the new determinant of competitiveness of industrial enterprises. This challenge can be met by Morocco because it has considerable energy assets as confirmed by some specialists: "In terms of renewable energy, Morocco has considerable assets; it has significant resources that can overcome its lack of fossil energy resources especially in the production of electrical energy, which has become nowadays, the main vector of any economic and social development. With a wind potential estimated at 25,000 MW throughout the territory, a solar potential with more than $3000 \mathrm{~h} /$ year of sunshine or an irradiation of about $5 \mathrm{kwh} / \mathrm{m} 2 /$ day, Morocco aims to achieve $42 \%$ of its electrical power from renewable sources by 2020 (14\% solar, 14\% wind and 14\% hydro "(Fassi-Fehri.O. (2014) [13]

\subsubsection{Organizational competitiveness (OC) :}

In what follows, we will discuss the notion of organizational competitiveness, focusing our investigation on structural competitiveness, as this is what is concerned in our case. This will allow us to understand the impact of the TDI on the OC.

\section{a. Competitiveness :}

Defined very generally, the concept of competitiveness refers to the ability of an economic entity to carry out an

\footnotetext{
${ }^{4}$ Personal definition
} 
activity and generate income, the activity being subject to competition. According to (Dejardin, 2006) [10] :

\section{b. Structural competitiveness :}

Structural competitiveness is the ability to impose one's products or services independently of their price (quality, innovation, after-sales services, brand image, delivery times, ability to adapt to a diversified demand, etc.). "This type of competitiveness therefore depends on quality, innovation and reputation" (Dejardin, 2006) [14]

\subsection{9. the aeronautical industry (Al) :}

We will limit ourselves to definitions that refer to our field of study, which is the knowledge economy. We will retain the one given by the honorary president of GIMAS $^{5}$ (EL ANDALOUSSI, 2015[15] who defines the aeronautical industry as follows "it is the set of professions and services that contribute to the manufacture and maintenance of aircraft. It is a sector at the heart of the knowledge society. It is a cutting-edge sector that generates and induces others such as safety, composite materials and engineering. We also retain the one that considers it as a sovereignty industry (Muller, 1988; Michot, 2004, Talbot, 2018).Moreover, it is this criterion that justifies our choice of this sector because we will propose it to be a pilot for the implementation of STDI within the framework of the model of projected development. In the same order of ideas, the aeronautical industry (Al) is defined as a high-tech industry that is characterized by complexity and sophistication as it is explained by (Hattab, 2009) [16]. It is therefore clear from these definitions that $\mathrm{Al}$ is an issue for a developed nation that must master the complex know-how that this activity requires, in order to ensure its technological independence (Muller, 1988). (Op. cit.).

1.1.10 Ecosystems and environment. Nathalie VaillantGaveau(2011) [17]

\section{a. Ecosystem :}

Historically, the notion of ecosystem arose from the concept of biocenosis: populations that live together (populations are linked to each other); then the notion of ecological succession (populations are linked to environments).

An ecosystem is a dynamic set of living organisms (plants, animals and micro-organisms) which interact with each other and with the environment (soil, climate, water, light) in which they live

b. Environment :

The environment is defined as "the set of elements (biotic or abiotic) which surround an individual or a species and some of which directly contribute to meeting its needs", or even as "the set of natural conditions (physical, chemical, biological) and cultural (sociological) likely to act on living organisms and human activities "

\footnotetext{
${ }^{5}$ Groupement des industries marocaines aéronautiques et spatiales
}

Indeed, the concept of environment refers to the natural setting (biotope) in which organisms (biocenosis) interact. Moreover, it is possible to say that the action of man has an environmental impact.

b. Ecosystem-Environment : What relationships ? The simplest definition of an ecosystem is that it is a collection of living things that live within a specific environment or setting and interact with each other within and with that environment.

The environment refers to the surroundings, while the ecosystem is the interaction between the environment and the living organisms. The environment is the area where living organisms live. The ecosystem is the community where biotic and abiotic elements interact with each other.

\subsection{Definition of a theoretical framework :}

The literature review above shows that the concepts that constitute the key words of our problem are multidisciplinary. Most of them are defined from strategic management theories, while others, for the sake of contextualization, have been defined on the basis of governmental and institutional documentation. Those that are new, such as STDI, STIA and transversal ecosystems, have been defined personally.

\section{Methodological framework for a logical connection of concepts : an application to the aeronautical industry in Morocco}

This part will try to establish logical links between the concepts defined above. The objective is to arrive at formulating a problematic which will be the object of a conceptual modeling of the STIA that we propose. It is more precisely a question of detecting the explanatory and intermediary variables of the $O C$ which is our variable to explain. For that we must mobilize a methodological device constituted by the methodological approach to be followed and the theories of the strategic management to be mobilized.

\subsection{Methodological framework and theories to be mobilized}

\subsubsection{Methodology}

To conduct our study, we will adopt an exploratory qualitative approach based on the interpretation of the data we collected mainly through documentary research and non-participant observation. This method should allow us to contextualize the problematic in the Moroccan context, and then to establish logical connections between concepts.

For the contextualization we will use the methodology of context and contextualization as developed by the Marrakech School (DOHA.S.and Louitri.A., 2020) Op.cit. We justify our recourse to this approach by our conviction that an organization's strategy is the result of a process embedded in a context, as confirmed by 
(Pettigrew, 2003) [18] "an organization's strategy is the result of a process embedded in a context" and that certain elements of the context can influence the functioning of a model, as stated by Jacques Igalens ".... Certain elements of the context can play a more active role in the functioning of the model or in the hypothetical articulation between the explanatory variable and the variable being explained.

This methodology should also allow us to contextualize the strategic management theories of strategic management that we will mobilize in order to produce actionable managerial knowledge knowledge as specified by (Chafik BENTALEB, 2020)[19]: "The managerial theories, mostly theories, mostly AngloSaxon, mobilized are sometimes insufficient to understand and explain all

to understand and explain all the organizational reality and the experience of localized actors in specific contexts.

In this context we will mobilize at the appropriate time some theories that we have deemed adequate.

\subsubsection{Theories used}

The second part of our methodology consists of the mobilization of a few strategic management theories that we have judged to be adequate for our subject. In this context, we believe that the theory of business ecosystems and the theory of resources (RBV) are more appropriate. We will also use the theories of dynamic capabilities (DC) and organizational capabilities (OC) to find links between the concepts in a managerial logic. The objective is to build a solid theoretical foundation for our researchto place it in the framework of management sciences and strategic management.

\section{a. Business Ecosystem Theory (BET)}

The objective behind the mobilization of this theory is the understanding of the theoretical foundations of the new industrial strategy of Morocco established under the INAP. The latter is materialized by the establishment of efficient ecosystems for the competitiveness and performance of Moroccan industry.

This concept of ESA is strongly mobilized in recent years by the international academic community in general (Moore, 2005, lansiti and evien, 2004, Teece, 2007) and French in particular (Isckia, 2006, Gueguen and Torrès, 2004, Pellegrin-Boucher and Gueguen, 2005, Ronteau 2009). Quoted by M.ETTAIBI and MOKHTARI .B [20].

$A$ business ecosystem is therefore, according to (James Moore 1996), an "economic community" around a pivotal firm "whose members include suppliers, producers, competitors and other interested parties. Their capabilities and roles co-evolve over time, and tend to align with the directions chosen by one or more core companies. It is this coevolution and alignment that allows us to speak of an ecosystem, by analogy with an ecological ecosystem.Daidj .N. (2011) [21]. This analogy between the ecological and industrial ecosystem will be the subject of one of our future work.
What interests us here is that the ESPs set up in Morocco find their academic legitimacy in strategic management theory. These Moroccan-style ecosystems are therefore well founded at the theoretical level because they are compatible with the industrial business ecosystems analyzed by the major authors of managerial theory. This theory will be useful in our work of designing the transverse ecosystemic device that we propose as the basis for the implementation of STIA 4.0.

\section{b. Dynamic Capability (DC) and Organizational Capability (OC) theories}

The above literature review shows that the business ecosystem is a suitable framework for analysis of our problem.

To achieve organizational objectives within an BET, DCS are mobilized. This concept was developed in the 1990's. Its first definition is given by Teece et al. "The ability of a firm to integrate, build, and reconfigure internal and external competencies to cope with rapidly changing environments" (Teece, Pisano and Shuen, 1997) OP.cit. Like the DCs defined above, OCs are also implemented to achieve goals in a logic of interorganizational cooperation. From this perspective, this concept is defined by Day et al. "OCs are collective and socially embedded constructs (Day, 1994 ; Saint-Amand and Renard, 2004 ; Schreyögg and Kliesch-Eberl, 2007). They are distinct from resources, skills and knowledge, which are isolated assets, and are thus materialized by complex sets integrating several of these three elements (Day, 1994 ; Grant, 1996 ; Saint-Amand and Renard, 2004 ; Schreyögg and Kliesch-Eberl, 2007). " Quoted by MOKHTARI B. and ETTAIBI M. (2021) [22-23]

It is the establishment of an integration mechanism allowing the coordination of activities to achieve a goal. It is precisely this configuration that is envisaged in the object of our research. Companies in the aeronautical industry must collaborate by implementing a knowledge management system or KM.

\section{c. Resource theory :}

To deal with our subject, we have mobilized another approach in addition to those mentioned above, namely the Knowledge Based View (KBV) (Grant, 1996), which is derived from the Resource Based View (RBV) (Barney, 1991 ; Wernerfelt, 1984). The latter considers intangible assets, notably skills, abilities and knowledge, as the sources of sustainable competitive advantages for companies. According to $\mathrm{KBV}$, knowledge is now the most strategically important resource for the company that should be managed and valued (Laid Talbi Chehla, 2018) [24].

\subsection{Application to the aeronautical industry in Morocco (IAM) : A proposal for the articulation between the concepts}

2.2.1. Relationship between the knowledge and digital ecosystems. 
This is the main relationship that we seek to model, we specify that our thread of all the research of the links between concepts is the knowledge management (KM). We will thus seek to demonstrate how the KM explains the other variables. Our demonstration will of course be done by adopting the methodological device mentioned above.

The review of the literature shows that knowledge management according to the information systems (IS) approach establishes a relationship between KM and TDI insofar as knowledge needs an IT support to store, analyze and share it and conversely the IS needs knowledge for its technological, organizational and managerial innovation needs. To transpose this relationship on the aeronautical industry in Morocco (AMI) taking into account the Moroccan specificities and mobilizing the dynamic and organizational endogenous capacities, we recommend to register the AMI in the context of the knowledge economy knowing that this awareness exists among the Moroccan aeronautical actors as it is explained by the definition given to the Al by the president of GIMAS (op. cit.).

This relationship between the two ecosystems is established if we take into account the complexity and sophistication of the aeronautics industry. These two characteristics require specific knowledge for innovation. The latter does not only concern the production processes but also the supporting digital components. It is at this level where KM impacts TDI. It remains to be specified that the knowledge to be mobilized is of the Data type provided by the Data Center. Thus to face the challenge of the transition to the aerospace industry 4.0, companies in the aerospace industry in Morocco (EIAM) have no choice but to implement a STIA of KM origin. The latter consists in knowing how to exploit the data of Big Data to succeed in the transition to Industry 4.0, artificial intelligence, augmented reality, 3D printing and connected objects. The challenge is not only to succeed in this digital transformation by implementing these tools but to succeed in the TDI which will integrate as its name indicates all components. Among the most important is the human component. This last one is the Human Capital $(\mathrm{KH})$ of $\mathrm{KM}$ origin which must be the support of the TDI. This means concretely that it is necessary to put in place human skills armed with strategic digital knowledge. This challenge can be met by the aeronautical actors by improving the training of technicians from training centers dedicated to aeronautics as the Institute of Aeronautical Trades (IMA) and the specialized institute of aeronautical trades and logistics (ISMALA) ${ }^{6}$. This can be programmed under the PAI 2.0

\subsubsection{Relationship between knowledge and innovation ecosystems}

Innovation is the key to achieving OC in all organizations. Based on the established relationship between KM and innovation, from our literature review ; the relationship between these two ecosystems is obvious. Its application for $\mathrm{MRI}$ is quite possible as long as aeronautical training institutions are available. The only thing left to do is to encourage research and development to make KM innovation. Concerning its contextualization, it must be operationalized within the framework of the ESP which are a Moroccan specificity. This innovation, having for finality the digital transformation, can be made by the Moroccan competences constituted by the young people and the digital Start -up. The latter are well known in these fields and can take up the challenge.

\subsubsection{Relationship between innovation and renewable energy ecosystems (ECONOV- ECOSER)}

ECONOV must give priority to renewable energy innovations. These are available in Morocco. They are characterized by the diversity of their source. These assets of Morocco must be exploited by new technologies developed by ECONOV for the benefit of ECOSER. This should allow the aerospace industry in Morocco (IAM) to meet the challenge of decarbonization as a new factor of competitiveness

\subsection{The impact of TSAI 4.0 on the competitiveness of companies}

This relationship is the core of our analysis. We seek to demonstrate to what extent digital technology has a positive or negative impact on the competitiveness and organizational performance of the aerospace industry in Morocco. The review of the literature that we have conducted shows that this relationship exists and that the Digital is a source of Competitiveness As Porter and Millar (1985) point out "ICT is a tool for coordination between the various activities of the chain of production and distribution, but also for developing competitive advantages and new strategies. "BELLO. P, (2019) [25]. ECODIG specific to the aviation industry will help to maintain and boost competitiveness within EIAMs

\section{Proposal of a conceptual model}

\subsection{The formulation of the theoretical and conceptual research model: variables and hypotheses}

The objective here is to present the theoretical model on which our research is based. A model is considered as a "formal representation of ideas or knowledge about a phenomenon. These ideas are expressed by a set of hypotheses about the essential elements of the phenomenon and the laws that govern it" Grawitz (2001). Thus, the purpose of modeling is to simplify a reality or a problem through a representation in graphic

\footnotetext{
${ }^{6}$ Institut des métiers aéronautiques et Istitut Spécialisé des métiers de l'aéronautique et de la logistique.
} 
(or mathematical) form. In other words, it is a simplified and symbolic diagram intended to provide a rigorous reasoning framework to explain a reality. Quoted by (MOKHTARI B. \& ETTAIBI M. ; 2021a) [26]

From this point of view and on the basis of the interconcept connections explained above, we synthesize the relations existing or likely to exist between the different

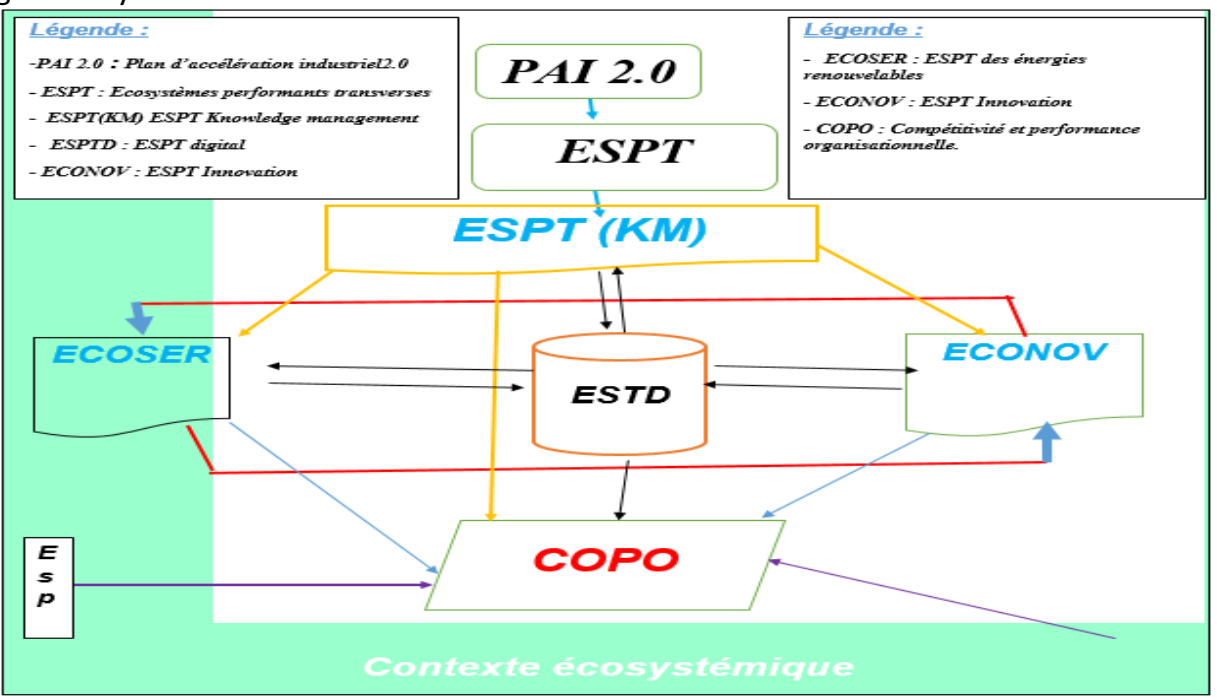

Source : Authors' design

Figure 1 : Relationships between the ESPTs for the design and implementation of an STDI in an ecosystem context In the design of the model, the variables are chosen according to their relevance in the design process of the STDI.

In our conceptual model, the COPO is considered as a dependent variable, i.e. to be explained, and the STDI as an independent or explanatory variable. But the causal relationship between these variables is not direct because it is mediated by two other variables (Baron and components of the TSID in the following synoptic diagram :

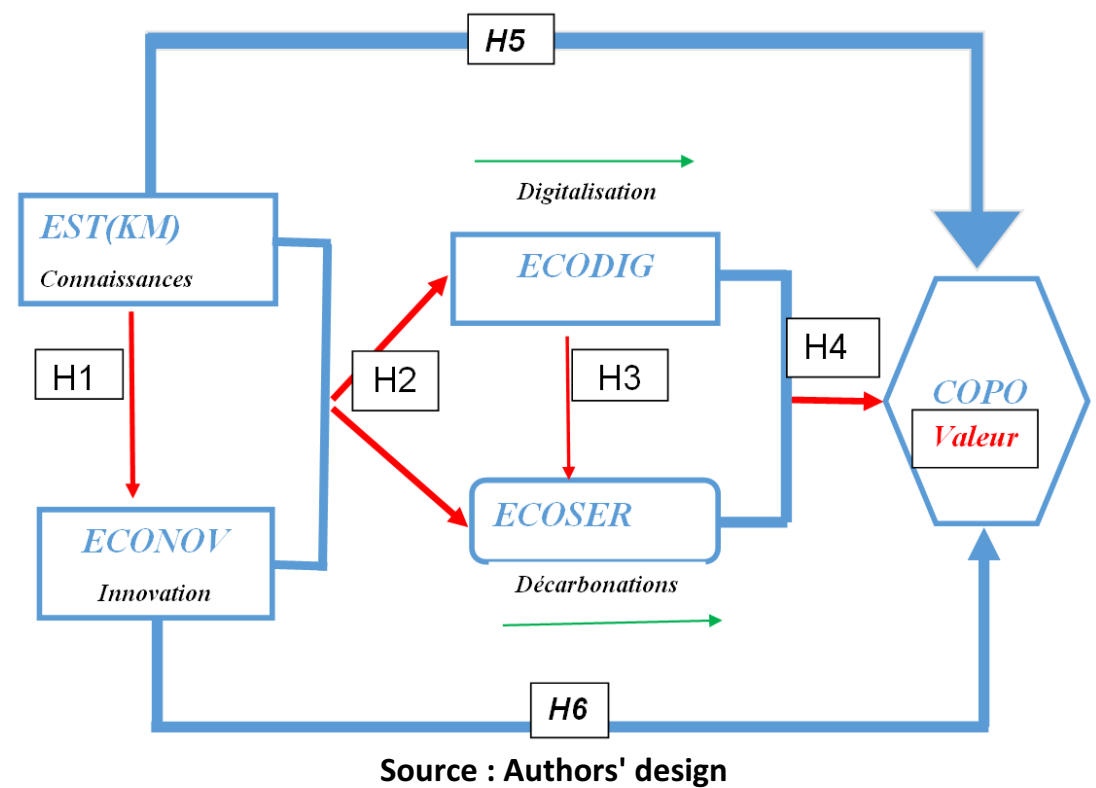

Figure 2 : Simplified Conceptual Model of STDI design and implementation in an ecosystem context 


\begin{tabular}{|l|}
\hline$\underline{\text { Légende : }}$ \\
EST $\mathrm{KM}$ : Ecosystème transverse \\
du Knowledge management \\
ECONOV : Ecosystème transverse \\
d'innovation \\
ECODIG : Ecosystème transverse \\
digital $\quad:$ Ecosystème transverse \\
ECOSER \\
des énergies renouvelables \\
COPO : Compétitivité et \\
performance organisationnelle.
\end{tabular}

Table : important abbreviations

\subsubsection{Model Assumptions :}

In hypothetico-deductive research, postulates or general principles are asserted in hypotheses. A hypothesis can be considered as a possible answer to the research question since it is an assertion or an unproven proposition (Garwitz, 2001) op. Cit. It is in a way an advanced basis of what we are trying to prove, that is to say, the preforma formulation of conclusions that we intend to draw and that we will try to justify and demonstrate methodically.

Below are the 6 hypotheses that could guide the construction of the model: They seek to link the digitization of $\mathrm{KM}$ origin to the $\mathrm{COPO}^{7}$ in the framework of the proposed STDI.

$\mathrm{H} 1$ : There would be a positive relationship betweenEST(KM) and ECONOV. It is a relationship between knowledge and innovation.

- $\mathrm{H} 2$ : There would be a positive relationship between the combination [(ESTP(KM), ECONOV)] and the ecosystem couple (ECODIG, ECOSER). The knowledge and innovation ecosystems would have a positive impact on the digital and renewable energy ecosystems.

- H3 : ECODIG would have a direct positive impact on ECOSER. The digital ecosystem would directly impact the renewable energy ecosystem.

H4 : The combination (ECODIG, ECOSER) would lead to better competitiveness and organizational performance (COPO). The digital ecosystem and the renewable energy ecosystem would directly involve the performance and competitiveness of companies in the sector.

$\mathrm{H} 5$ : EST(KM) would have a direct and indirect positive impact on improving COPO. The knowledge ecosystem would have a positive impact on the competitiveness and performance of companies

$\mathrm{H} 6$ : Econov of KM origin would have a positive impact on the improvement of COPO. The knowledge-based innovation ecosystem would positively influence COPO

\section{CONCLUSION}

By espousing an epistemological posture of constructivist orientation (Thietart et al (2014 p 24)[28], our study is closed by the proposal of a research design for the implementation of the STIA within companies of the aeronautics industry in Morocco. Our proposal is a response to the call for reflection [29] launched by the GIMAS on the future of the aviation industry. It is also in line with the resolutions of the last meeting of the General Assembly of GIMAS [30]. It is also in line with the perspective of a collaborative research between the academic world and the practitioners according to a "dialogic" model (Marie-Josie-Avenier, 2018)[31] .

By taking the perspective of "local to local"[32] our conviction is strong that the challenge of Aeronautical Morocco 4.0 [33] can be met and this, despite the complexity of this industry of sovereignty (Muller, 1988 ; Michot, 2004[34]). Our contribution is to show how to develop it for its simplexity by own and endogenous resources in the Moroccan context despite its sophistication (Hattab, 2009). That is why we have proposed this integrative strategy that integrates, in addition to digitization, other resources based on dynamic and organizational capacities (Teece et all Op.Cit, 1997) and that takes into account the context and contextualization (DOHA .S.et Louitri .A. 2020) Op.Cit.

It remains to emphasize that the present communication is original by its new and innovative character.New because it is in line with the proactivity and the suppuration. Innovative because it proposes an organizational innovation by a new strategy.new strategy conceived within a sovereign sector likely to be pilot of all the national industry.

The strong point of our contribution is that it is developed based on theories and methodologies of strategic management, which give it a conceptual and theoretical basis giving it the strength to be accepted by the academic world and to be a managerial research actionable on the ground (Chafik Bentaleb, 2020) op. Cit.

\section{$\underline{\text { References }}$}

[1] https://lematin.ma/express/2019/majeste-roiadresse-discours-nation-loccasion-fetetro/320308.html. Accessed 6/16/2021 at 12:25 a.m.

[2] Teece. D J. Pisano. G and Shuen. A. (1997) " Dynamics Capabilities and Strategic Management ". Strategic Management Journal, Vol. 18:7, 509-533 PP

[3]Doha .S. and Abdenbi. L. (2020), Contexteet contextualization Mosaïque d'approchesen management. EMI 2020, Edition Management and innovation / Maroc. PP.283.

[4]Castro, M. \& Ollivier, G. (2012). Political ecology des discours environnementaux internationaux : le cas de l'approche par écosystème de la Convention sur la diversité biologique (CDB). Dans : Denis Gautier éd., Environnement, discours et pouvoir (pp. 87-110).

\footnotetext{
${ }^{7}$ Compétitivité et performance organisationnelle.
} 
Versailles, France : Éditions Quæ. https://doi.org/10.3917/quae.gaut.2012.01.008 $\underline{7 "}$

[5]Richard Jean-François. Paysages, écosystèmes, environnement : une approche géographique (1 tabl. 6 fig.). In: Espace géographique, tome 4, n², 1975. pp. 81-92; doi https://doi.org/10.3406/spgeo.1975.1542 https://www.persee.fr/doc/spgeo_00462497_1975_num_4_2_1542

[6] Hess, G. (2009). IndustrialEcosystem: The EpistemologicalDifficulty of Such an Analogy. Natures Sciences Sociétés, 1(1), 40-48. https://doi.org/

[7]Larrère, R. (2006). L'écologie industrielle : nouveau paradigme ou slogan à la mode. An article of the journal Les ateliers de l'éthique / The Ethics Forum Volume 1, Issue 2, Automne 2006, p. 103-113

[8]Louis.J.L (2018) .Knowledge Management. Volume 5, boucle créative, Edition ISTE. P : 3

[9]Aurélie .J. (30/Mars /2021). J'aime dire que la transformation digitale est finie. Entretien dans le cadre du Sommets du Digital du 5, 6 et 7 février 2018 (France) [online] http://www.influencia.net/fr/actualites/. consulted on 06/20/2021 at 06:51 am

[10] Elalamy.M.H (25Mars 2021). Nous préparons déjà un plan d'accélération industrielle 2.0 qui prendra le relais après 2020. [En ligne] https://www.challenge.ma/nous-preparons-deja-unplan-dacceleration-industrielle-2-0-qui-prendra-lerelais-apres-2020-117239/Consulté le 08/12/2020.consulted on $21 / 20 / 2021$ at $16: 51 \mathrm{pm}$

[11] SEDDIKI. A. (2021). Le plan d'accélération industrielle : quelle feuille de route ? : [Enligne] http://play.luxeradio.ma/show/track/_.consulted on 21/20/2021 at 17:51 pm

[12] Munerol, L., Cambon, L. \& Alla, F. (2013). Le courtage en connaissances, définition et mise en œuvre : une revue de la littérature. Santé Publique, 5(5), 587597. https://doi.org/10.3917/spub.135.0587.consulted on $06 / 20 / 2021$ at $07: 58$ am

[13] Fassi-Fehri.O. (2014), « Sources d'énergie renouvelables et transition énergétique : faits, défis et opportunités pour le Maroc » article publié dans les actes de la session plénière solennelle19 - 21 février 2014 Rabat Maroc. PP : 298.
[14] Dejardin, M. (2006) "Compétitivité structurelle ». Reflets et perspectives de la vie économique, tome " xlv, $\mathrm{N}^{\circ}(1)$, pp 5-13

[15] El ANDALOUSSI.I. (2015). 60 Minutes pour Comprendre l'industrie aéronautique au Maroc. [En ligne]

https://www.youtube.com/watch?v=9HRcKv6TgGM.con sulted on $06 / 20 / 2021$ at 08:58 am

[16]Hattab-Christmann, M. (2009) « Mutations dans l'industrie aéronautique française et nouvelles localisations au Maroc : Vers l'émergence de nouveaux territoires de l'aéronautique ? ". Géographie, économie, société, 3(3), 251- 274.

[17] Nathalie Vaillant-Gaveau(2011), Entre environnement et écosystèmes, une relation ambigüe.Atelierbabel. Faculté des sciences Reims France. https://babel.hypotheses.org > files > 2011/0. Consulted on 06/19/2021 at 22:52 pm

[18] Pettigrew AM, (2003) « Strategy as process, Power, and Change ", in Cummings, s, et Wilson, D, (2003b), Image of strategy, Blackwell Publishing, PP.301330

[19]BENTALEB .C, (2020) "Éditorial ", Revue Management \& Innovation, 2020/2 ( $\left.N^{\circ} 2\right)$, p.7-10.

[20] MOKHTARI .B \&M. ETTAIBI (2021). Le knowledge management(KM), nouveau vecteur de compétitivité : Application à l'industrie aéronautique au Maroc dans le cadre des écosystèmes performants(ESP).Dans GENERIS PUBLISHING Maison d'Edition Européenne. ISBN : 978-163902-353-0. "Performance des entreprises : vers quel modèle de création de valeur ? ».France, GENERIS PUBLISHING PP. 805-833

[21]. Daidj .N. (2011) « Les écosystèmes d'affaires : une nouvelle forme d'organisation en réseau ? ", Management \& Avenir, 2011/6 ( $\left.n^{\circ} 46\right)$, p. 105-130.

[22-23]. MOKHTARI B. \&ETTAIBI M. (2021) « Le management des connaissances(MDC) levier de compétitivité organisationnelle(COMO) : Cas de I'industrie aéronautique au Maroc dans le cadre du Plan Emergence.», Revue Française d'Economie et de Gestion «Volume 2 : Numéro 3» pp : $149-178$

[24] Laid.T.C (2018). "Le Management des connaissances, levier de l'innovation managériale dans les entreprises apprenantes. " Gestion 2000, (Volume 35), p. 73-101

[25] BELLO. P, (2019) « le digital dans la formation de la performance des petites et moyennes entreprises des pays en voie de développement "XXVIIIe Conférence 
Internationale de Management Stratégique, Dakar, 1114 juin 2019(Senegal), pp : 31.)

[26]MOKHTARI.B. et ETTAIBI.M. (2020) « La maitrise des risques (RM) par le knowledge management : Application à l'industrie aéronautique marocaine dans le cadre du plan d'accélération industriel 2.0 (PAI 2.0) »Actes du « 1st Workshop on Modeling for Risk Management » Éditeur : LAREMEF, ENCG Fès, USMBA Fès, ISBN (Papier) : 9789920-32- 631-5, ISBN (Électronique) : 978-9920-32-6605, PP.35-44

[27] Baron, R. M., \& Kenny, D. A. (1986). "The moderator-mediator variable distinction in social psychologicalresearch: Conceptual, strategic, and statisticalconsiderations. " Journal of Personality and Social Psychology, 51(6), 1173-1182

[28] Raymond - Alain Thietart et al (2014) « Méthodes de rechercheen management ». Ed. DUNOD.
[29] Industrie.MA( 2020)/https://industries.ma/legimas-lance-une-reflexion-sur-lavenir-de-lindustrieaeronautique-au-maroc/.consulted on $21 / 20 / 2021$ at 18:51 pm

\section{[30-32-33] Challenge.ma (2020)}

|https://www.challenge.ma/aeronautique-les-detailsde-la- nouvelle-orientation-strategique-du-gimas$169338 /$.

[31]Avenier, M.- J., \&ParmentierCajaiba, A. (2012). The dialogical model: developing academic knowledge for and from practice. European Management Review, 9(4), 199-212.

[34] cité par Talbot, D. (2018). L'industrie aéronautique civile européenne : vers une banalisation ? Revue d'économie industrielle, 4(4), 131151. https://doi.org/10.4000/rei.7699 